\title{
Popular Music and Gender in Jamaica
}

\section{Beverley J. Anderson, Eastern Connecticut State University \\ Winston E. Langley, University of Massachusetts, Boston}

Recent discussions about Jamaica's popular music -- reggae -- have focused on the kinds of images of women that have been created by reggae artists, especially those who focus on "dance hall" reggae. Content analysis is used here to examine the lyrics of thirty five songs created and performed between the mid-1960s and the end of the 1980s in an attempt to determine whether the images of women in reggae lyrics are largely negative and may contribute to norms that foster discrimination against women.

Social respect for and political support of the norms of equality and nondiscrimination are critical, if human beings are to enjoy a life of dignity. The postWorld War II efforts to effect a new international order have not only sought to codify those norms, but have, in the case of women, devised very specific international instruments designed to recognize the special actions that must be taken if women are to participate on equal terms with men in the political, social, and economic life of the communities in which they live. ${ }^{1}$ Indeed, these instruments recognize that failure to ensure equality and non-discrimination against women not only undermines the latter's sense of worth and dignity, but creates obstacles to the socioeconomic growth and prosperity of societies, inasmuch as such failures make it difficult to marshal women's potential in the service of society.

Although references above to international instruments imply actions by nation-states to help realize the ends (including dignity) sought qua equality and non-discrimination, it generally has been acknowledged that the role of nongovernmental institutions -- churches, schools, and unions for example -- as well as certain professional groups such as artists would be decisive. The role of artists would be particularly important because they create the images (the mental maps) by which people see, think, feel, and evaluate their being.

This paper seeks to identify and examine some images of women created by Jamaican artists (popular musicians) between the middle 1960s and the end of the 1980 s, to determine whether and to what extent these images contribute to the diminution of the promotion of norms of non-discrimination and equality. The years with which the study is principally concerned are those of the 1970s and the 1980s because (1) they encompass the United Nations' Decade for Women (19761985), during which societies were to make particular efforts to ensure equality for women, and (2) it was during this period that reggae became the most representative form of Jamaican popular music. However, some attention also is given to the 1960 s in order to determine if there were continuities in the images uncovered. 


\section{Historical and Theoretical Perspective}

\section{Women in Jamaican Society}

The history of women in Jamaica and throughout the Caribbean best can be interpreted from the perspective of a legacy of slavery, colonialism, and postwar independence. ${ }^{2}$ To a large extent this has led to a current reality of formal internal political independence conjoined with external economic dependence. On an interpersonal and familial level, Caribbean peoples have evolved a curious structure of male/female relationships rooted in their historical legacies.

Massiah $(1986,157-8)$ offers an instructive point of view on the position of women in the Caribbean:

One of the major legacies of a history of slavery and colonialism in the Caribbean is the continuing struggle to develop new structures out of the institutional arrangements and behaviours inherited from both the colonizing and the slave-supplying societies. In the area of male/ female relations, the region has inherited from its European roots a philosophy of patriarchy and male domination. From its non-European roots, it has acquired a tradition of "matricentredness," which, though adhering to the whim of male dominance, also pays tribute to the central role of women. During the years of slavery, the traditions existed side by side. Women at the top of the pyramidal ethnic and class structure accepted and were dominated by [the] European tradition of male supremacy. The mass of black women at the bottom of the scale attempted to perpetuate as much as possible their African traditions, but, the slave code granted equal status to male and female slaves... In the middle of the system were the mulatto women, less bound by traditions of either group ... many were determined to maintain a degree of personal independence in their activities, including their relationships with men.

This theme is further developed by Safa (1986). Safa points out that from the early days of slavery, women's economic role as workers and providers was not seen as incompatible with their reproductive role as wives and mothers. She goes on to point out that women of ten were expected to bear primary responsibility for financial support of their families. So, at least in the lower and lower-middle classes, women experienced considerable economic autonomy and thereby reduced dependency on men. Brodber (1986) also points out that Jamaican women enjoyed a basis for economic independence in the form of access to land through inheritance. In cases where a woman's land was insufficient to provide a living, she would gain access to the land of her male partner, which she would cultivate with "female crops" for additional income. Brodber points out that to a large extent, Jamaican women between 1900 and 1946 identified female economic independence (from males with whom they are involved emotionally) as crucial to their self-esteem $(1986,44)$. 
Massiah (1986) suggests that of all the contradictions in the lives of Caribbean women perhaps the most contradictory involves the male and female perceptions of each other and themselves. This contradiction is rooted in traditional stereotypes of male domination. Women, on the other hand, perceived a need to exploit every available opportunity in order to maintain their household units and preserve their individual independence. She states that:

Men express a reluctant admiration for their women's initiative but perceive a need to prevent them from assuming control lest they themselves lose what power they had. Accordingly, perceptions of each other display mutual distrust and suspicion as each attempts to influence the system of male supremacy they both accept (Massiah 1986, 161).

Barrow $(1986,58)$ elaborated Caribbean males' perceptions regarding male/ female relationships:

The males argued that $C$ aribbean man perceives women as existing for his sexual pleasure. The tendency to be simultaneously involved with more than one partner is perceived as natural to man -- "to keep you knowing who is man" -- but not to a woman. For their sexual performance men are complimented as "hard seeds," while women become "whores" and are "dragged in the gutter." The men justify their behaviour particularly within marriage where women, they argued, ... relax their standards and become fat, lazy and "bossy."

\section{Popular Music as a Social Problem}

In the broader context, the issues raised in this work can be divided into three distinct theoretical categories. One is the view that certain popular music constitutes a social problem, in that it is, in certain ways, socially injurious (Berger 1947; Biafra 1987; Firth 1981, 1986; Leonard 1962; Chapple and Garofalo 1977; and Denisoff 1975). In a general sense, reggae can be seen to have contributed to social ferment and even division, as have jazz, rock-and-roll, and (currently) rap music in their formative years. In specific, reggae music in Jamaica -- and, indeed, other popular music in the Caribbean, such as calypso -- is regarded by many to pose a problem in the form of song lyrics that are offensive to women, and harmful to their place in society. The work of Elder (1968) on "The Male/Female Conflict in Calypso" is particularly instructive.

We contend here that even from an objective point of view, the lyrics of reggae music are in large deleterious to the image of women, and as such diminish their attempts to achieve dignity and equality in the Jamaican society and throughout the Caribbean region. 


\section{Politics of Language}

A second theoretical strand worth mentioning is the literature discussing the "politics of language," and, more specifically, language as control. Here we look to the works of Bloch (1975), Pateman (1980), Ardner (1975, 1978), Cameron (1985) and Fraser and Cameron (1989). The issues that emerge from this literature inform the extent to which language is used as a dominating force in society, and the extent to which women are controlled and victimized by language. The relationship to the concept of "mutedness" as it relates to women is central to this discussion. Grillo $(1989,15)$ points out that mutedness is not simply silence, but rather

... a structural situation in which a group may be muted "simply because it does not form part of the dominant system of the society." What is said has to be articulated, if it is to be articulated at all, through the dominant male mode, though the mutedness concept may also be applied to those in a subordinate class position.

Although some theories on social class will indicate that females occupy positions at all social class levels, there remains the contention of many scholars that as a category of persons they occupy positions lower than males in each category. Such a point of view has led Anderson $(1986,291)$ to pose the question: are women the niggers of the world?

\section{Reggae as Revolutionary}

The third category, and the one that this study centers upon, involves the area of scholarship commonly referred to as liberation theory/theology. Among works that inform this section are Arche (1982), Sacred Congregation for the Doctrine of the Faith (1984), Berryman (1987), Horsley (1987), and Amin (1986). In this context, the authors examine reggae music -- which at its origin espoused a message of liberation -- in terms of the less-than-liberating depiction of women that occurs especially, though not exclusively, in the reggae form known as "dance-hall reggae."

As reggae evolved from and through the music forms called mento, "the ska," and "rock steady" to its present form, it has, like other forms of popular music, engaged in social commentary. However, unlike other popular forms, such as Trinidadian Calypso and the American blues, reggae transcended social commentary and courted the political. This courtship is not to be confused with the allusive political satire of calypso, or the implied political message frequently couched subtly in the overwhelmingly romantic lap of certain "rock steady" music; nor are we dealing with themes of survival and accommodation normally found in popular art. 
Rather, we are referring to the frontal engagement of the political, with an explicit focus on transformative discourse (Kothari 1987, 227-290). The thrust of the transformation sought, in turn, was such that reggae largely frowned upon the partisan struggles of the present, because the possibilities it preached fundamentally could not be reached through any outcomes to which those struggles might give birth. The issue of cultural identity should be a helpful illustration.

The rastafarian movement, out of which reggae came, felt that Jamaicans suffered from a crisis of cultural identity -- a crisis that, on both the individual and national level, could be expressed as what social psychologists call cognitive dissonance (Aronson 1972, 92-3). Price $(1979,149)$ explains Rastafarian philosophy thusly:

... They believe that a nation that is ashamed of itself can create nothing, and that a nation that creates nothing can achieve nothing, least of all its own liberation. A valid sense of identity can only come from deeply felt national consciousness and from pride in its own values and achievements.

To the Rastafarians, Jamaicans were (and perhaps still are) mired in a traditional Christian religion that is defined in terms of a racially white self-image -- the very image that is the source of the black person's oppression. To say that such a religion can be a source of liberation for blacks invites contradiction. Similarly, the broader social structure that is controlled by the "wicked, established forces" (Babylon) cannot be the inspiration for, or agent of, the good society. Hence, reggae sought to reconstruct Christianity in the image of African culture -- the culture of the slave (or of children of the slave), the outlook of the oppressed, not of the oppressor. The reticulated ties between religion, politics, and reggae in Jamaica are reflected in reggae artist Peter Tosh's response to a question about why Jamaican political leaders have paid so much attention to reggae:

Well, dem have to listen to what the people say to know the people's view. Reggae is telling them what's on people's mind, seen? Cause the singers and players of instruments are prophets of the earth in this time. It was written: Jah say, 'I will call upon the singers and the players of instruments to tell the word and wake up the slumbering mentality of the people.' Seen? (Davis and Simon 1983, 48).

The revolutionary quality of reggae may be seen not only in its effort to effect social transformation but also in terms of the "bottom up" direction in which that transformation seeks to take place. It is generally acknowledged that revolutions mostly are middle-class phenomena, and that revolutions sponsored by such strata seldom, if ever, seek or achieve comprehensive, fundamental change. Conversely, the revolutions that are pursued -- if not achieved -- by persons who are from the lower socio-economic classes generally seek fundamen- 
tal social transformation. Whether or not these theoretical claims are accurate, reggae originates from the slums of Kingston, and has sought to promote comprehensive and fundamental changes in Jamaican society, while engaging or reflecting in its musical pulse almost every thought, texture or tone of feeling and almost every aspect of the human condition. So, for example, one finds -- in the work of the same artist -- hope and optimism as reflected in "You Can Get It If You Really Want," juxtaposed with growing self-doubt in "Many Rivers To Cross;" the estrangement and near existential despair of "Sitting in Limbo"3 along side the gritty rallying cry in "The Harder They Come" to reject the temporizing promises of the oppressors, and take action to realize social justice. ${ }^{4}$

In the works of another artist (we seek here simply to note the range of focus of a few individual artists, in order to suggest what the musical form as a whole does), one finds in "Get Up Stand Up" a renunciation of Christian humility and a call to fight for individual as well as collective dignity, an affirmation of Jamaica's cultural heritage and identity in "African," and the contention in "Equal Rights and Justice" that unless these are present, one should reject peace as a value. To affirm the African heritage of the overwhelming majority of the population is to pursue the redemption of the authentic cultural self. Rejection of peace (often referred to in domestic politics as law and order, or the established way of doing things) is nothing less than a call to war in the pursuit of social justice; certainly, such seems true of any call for "equal rights" in a society riddled by class and racial cleavages.

Other themes found in some of the above songs and in "Blackman Redemption," "Trench Town," and "Duppy Conqueror" include the possibility of finding dignity in the face of degradation, finding community and compassion in the presence of selfish individualism and passion, finding roots in the face of constant change, gaining spiritual fulfillment and completeness in the presence of material greed gone wild, and the chance of victory in the face of apparently overwhelming odds. Such themes in the aggregate are often complemented with underlying motifs of oppression, hope, loyalty, evil, love, homesickness, and quest for the new. But the most important attribute of reggae music is its transformative content, which seeks to move from commentary to rights, sees in degradation the seeds of dignity, and aims to build the fundamentally new. Such is the definition of revolution.

\section{Revolutionary Reggae and Women}

Despite the revolutionary nature of this popular music, only in one of the songs surveyed ("The Message") ${ }^{5}$ do the lyrics suggest any prospect for the betterment of women. To be sure, social movements of a revolutionary character do not, as such, inherently promise the liberation of women. Moreover, revolutionary movements, even when from the bottom up, not only may simply fail to improve the condition of women, but actually may contribute (at least in the short run) to a worsening of that condition. 
This study tests the contention of popular critics that in general, the lyrics of reggae not only do not support the advancement of women, but have contributed to the establishment and perpetuation of demeaning images of females in Jamaican popular culture and (therefrom) social discourse. We shall use dignity as the general focus of discussion, since the concept may be nominally defined to incorporate the attributes of equality, security, identity, and self-esteem.

A life of dignity (even when one is considered to have inherent dignity) is one that results from, among other things, being effective. Defined negatively, this is the capacity to escape impotence, to avoid being an object. Defined affirmatively, this means one's internalized sense of having the capacity to influence the outcomes of things considered important by one, to affect the conduct of others and of institutions. Viewed in a sociopolitical context, to be effective is to be codeterminer of actions that affect one, and to make others pursue alternatives that are not hostile to the ends one seeks. Being co-determiner is the basis not only of equality, but of security as well, since one, like others, enjoys control over what affects one's self. Having the capability to make others shape their behaviour in particular ways means that one sets limits in one's relationship with others. By setting such limits, one helps to create the basis for one's identity as well as one's own sense of significance. Of course, significance (and we are using that term interchangeably with self-esteem), the sense that one has worth, comes not merely from confidence in one's ability to give effect to one's interest and intentions but also from finding one's person and deeds appreciated and confirmed by others who are likewise esteemed and whose association is valued (Rawls 1971, 440). Significance, plus equality, security, and identity, are the major ingredients of a life of dignity (Langley 1985, 12).

\section{Data and Methods}

The use of content analysis in order to capture images of or attitudes toward groups, as is used here, has been well established. Lasswell (1942) studied the content of certain newspapers for usage of symbolic items such as "democracy," or "Jews," and whether their presentation was favorable or unfavorable. Other such studies have been done by Wright and Nelson (1939) and Davidson (1947), among others. Brodber and Green (1981) used this analytical technique for their study of "Reggae and Cultural Identity in Jamaica."

This study analyzed lyrics from a sample of thirty-five popular reggae "hits" performed and recorded during the decades of the 1960s, 1970s, and 1980s (see Appendix). The authors constructed a sampling frame consisting of 120 top reggae songs. In order to be included in the sampling frame, songs had to meet several sampling criteria, primary among which was popularity demonstrated by reaching one or more of the "top ten" music rating charts in Jamaica. These charts are The Daily Gleaner Hit Parade (a weekly top ten rating), The Daily Gleaner Reggae Top Ten (an annual top ten rating), The Star Record Shop, ${ }^{6}$ Swing Magazine ${ }^{7}$ Top Ten, 
and the Jamaica Broadcasting Company's annual Top One Hundred chart. Such charts are compiled on the basis of record and tape sales information provided by record outlets. Validation of the sampling frame (among other information) was obtained from expert sources such as disc jockeys and popular-music feature writers.

Of this sampling frame, 85 songs ( 71 percent) met the secondary selection/ sampling criteria, which was that the lyrics contained some discussion of the topic (females) under investigation. These 85 songs included ten drawn from the 1960s, 25 from the 1970s, and 50 from the 1980s. Consistent with this distribution, a proportionate stratified sample of 50 was selected using the percentage distribution 12:29: 59 for the three successive decades. From this percentage distribution, the actual number of songs included in the survey sample was 6: 14:30. An initial analy sis of the lyrics of these songs resulted in the elimination of 15 songs that were deemed to be ill-suited to systematic analysis for various reasons, principal among which was that lyrics were incoherent. The number of songs included in the final analysis was 35, distributed 5: 10: 20 over the three decades.

Such a proportional distribution of songs is consistent with the economic, social, and political context of each decade. The 1960s saw the emergence of the unique Jamaican musical sound and the crystallization of a recording industry in Jamaica, with concomitant promotion of Jamaican songs and artists both at home and abroad. The growth of the Jamaican recording industry has approximately doubled during each decade since. Thematically, the presence of females as subjects of song lyrics appears to have followed a similar trend. Although the burgeoning reggae of the 1970s introduced politics, revolution and salvation as major themes (Davis and Simon 1977; Brodber and Green 1981), the sheer increase in the volume of recordings since then has been accompanied by a proportional increase in lyrics about women.

The units of content analysis may be words, themes, characters, or items (Berelson 1952, 135). For the purpose of this study, themes were selected as the units of analysis. The authors identified six themes that were determined to be deleterious to the pursuit of a life of dignity for women. These images were:

Image:

(1) women as dependent

(2) Women as materialistic/avaricious

(3) women as house-persons

(4) women as sex-objects

(5) women as devious

(6) women as shallow/trivial
Exemplified In:

"Build Me Up"

"Minnie the Moocher"

"Woman Follow Man"

"Still Be a Lady/Titty Jump"

"Can't Tie Me"

"She Loves the Single Life"

The 35 songs will be analyzed in order to determine whether and with what frequency these themes are present in the popular songs. In order to make 
inferences regarding the intensity with which themes are projected, an internal frequency (repetition) measure also will be included. Internal frequency is defined as the recurrence of a theme three times or more in a song. Further, since the six themes are not mutually exclusive categories, more than one theme may be indexed for the same song.

Attempts then will be made to evaluate the images that emerge and to analyze them in terms of their broader social meanings; i.e., why these images have gained popularity, and what social implications the continued use of these images may have for the future. Because one wishing to assess the effects of the communication cannot confine one's analysis merely to the content of the messages, one's research design also should include evidence about the recipient of the communication (Holsti 1969, 36). Mention of musical reaction to the above themes by popular female artists, as well as the responses of women filtered through the mass media, will be presented in an attempt to suggest the possible effects these images have had on women in the Jamaican society.

\section{Findings}

Data from the analysis of these 35 songs revealed that 27 of the 35 , or 77 percent, contained at least one of the six identified negative images, while eight songs ( 23 percent) contained no negative images of women. Furthermore, 24 of the 35 songs ( 69 percent) demeaned women with internal frequency (at least 3 repetitions of the same theme in a song). It should be pointed out that the six categories of negative images tested for were far from exhaustive; therefore, many other negative references to women in the songs sampled are omitted here.

The distribution of specific negative images across all three decades is reflected in Table 1. As can be seen, stereotypes of women as sex-objects, devious, materialistic, and shallow each accounted for approximately one-fifth of all negative mentions, while the themes of dependency and (should be) house-persons each account for one-tenth of such mentions.

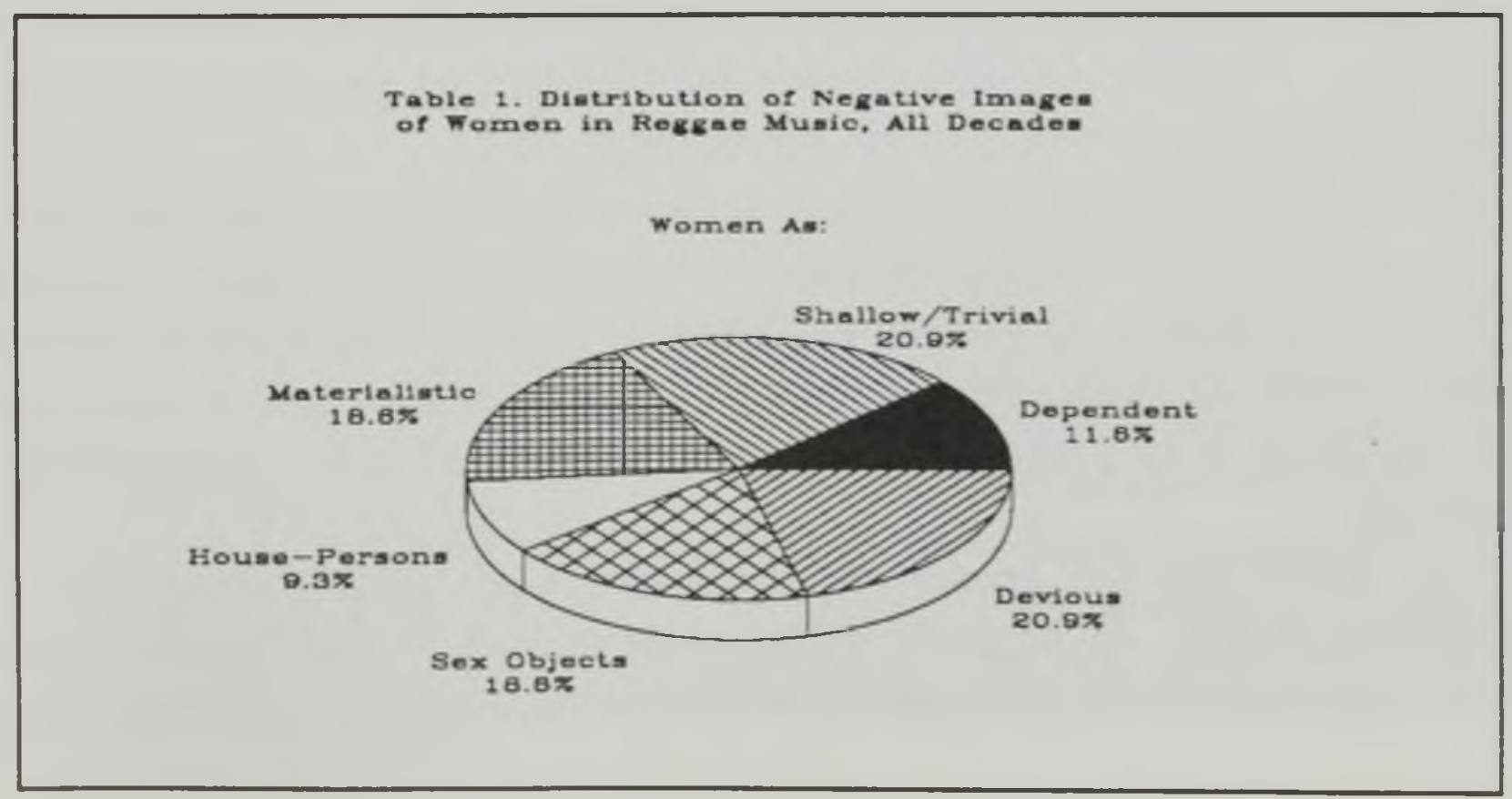


Each individual decade was dominated by these negative images. However, such negative stereotyping decreased slightly during the 1980 s to 75 percent, five percent lower than the high of 80 percent during the 1960s and 1970s. Interestingly, although the rate of occurrence of these images in reggae songs was slightly greater during the 1960s and 1970s, the internal frequency with which they were repeated was greater during the 1980 s. Specifically, while internal frequency was discovered for 60 percent of all negative themes encountered during the first two decades, the rate of such repetition during the latter decade was 75 percent of all cases. Thus, even though slightly fewer songs disseminated these images during the 1980s, those that did pressed their case more vigorously (see Table 2).

Table 2

Negative Images of Women in Reggae

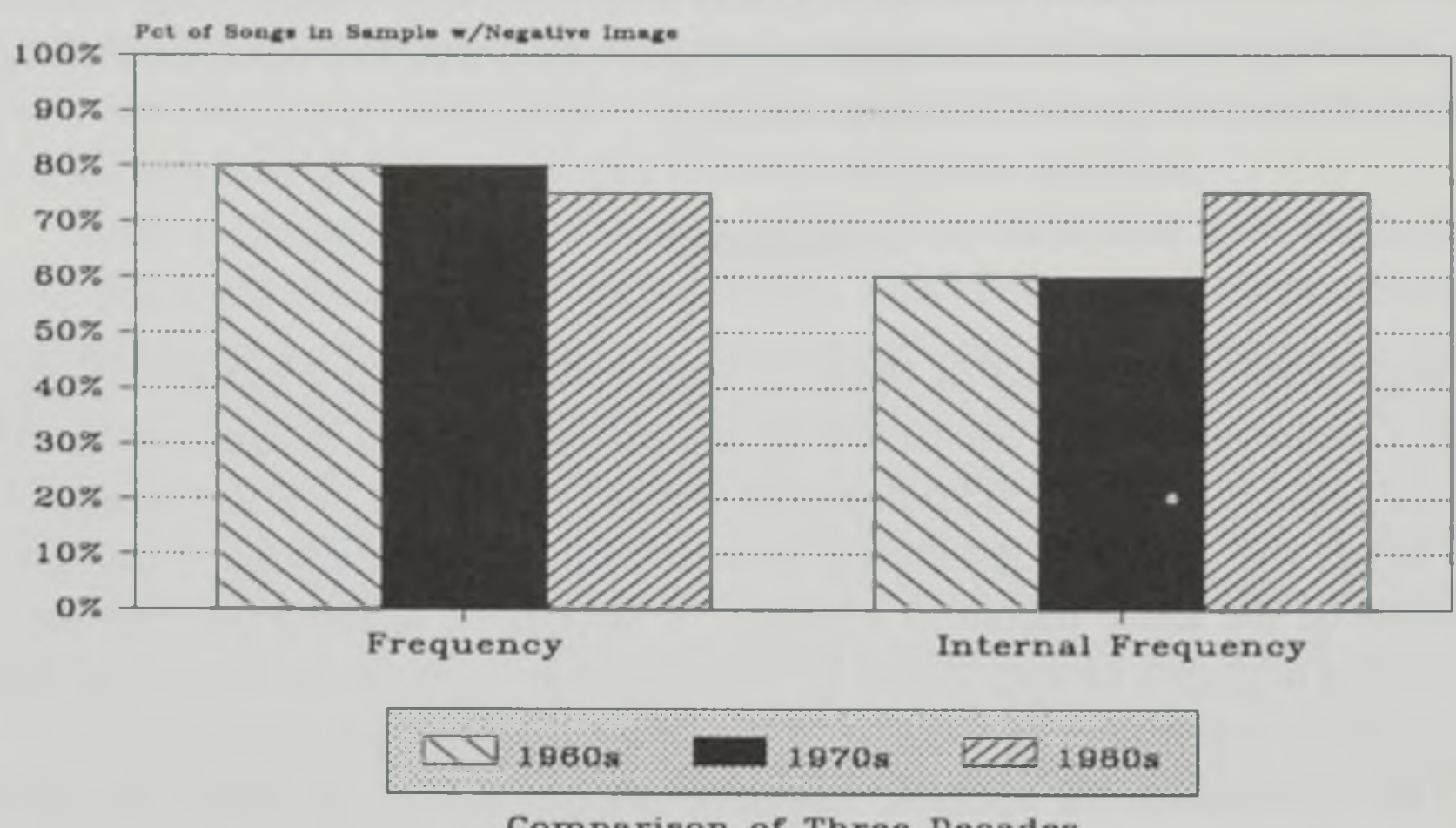

Analysis of the presence of the six individual images within each decade (see Table 3) revealed that during the 1960 s, only four images were popularly disseminated: women were characterized as sex-objects in 40 percent of the cases, while women as dependent, women as devious, and women as shallow each were expressed in 20 percent of the cases. The women as house-persons and as materialistic/avaricious themes were never expressed.

During the 1970s, the number of negative images expressed increased to five. The most recurrent theme was that women are devious ( 40 percent of cases), while women as shallow and women as dependent each occurred in 30 percent of all cases, women as house-persons occurred in 20 percent, and women as sexobjects occurred in 10 percent of all cases. Women as materialistic remained unexpressed.

The 1980s was the decade in which the scope of the negative images expressed was fullest. All negative images were voiced. Women as materialistic/ avaricious appeared for the first time (in 40 percent of all cases), women as shallow/ 
trivial and as sex-objects each appeared in 25 percent of the cases, the deviousness of women was told in 20 percent of the cases, and women were depicted as housepersons and dependents in 10 and 5 percent of the cases, respectively.

Table 3

Negative Images of Women in Reggae

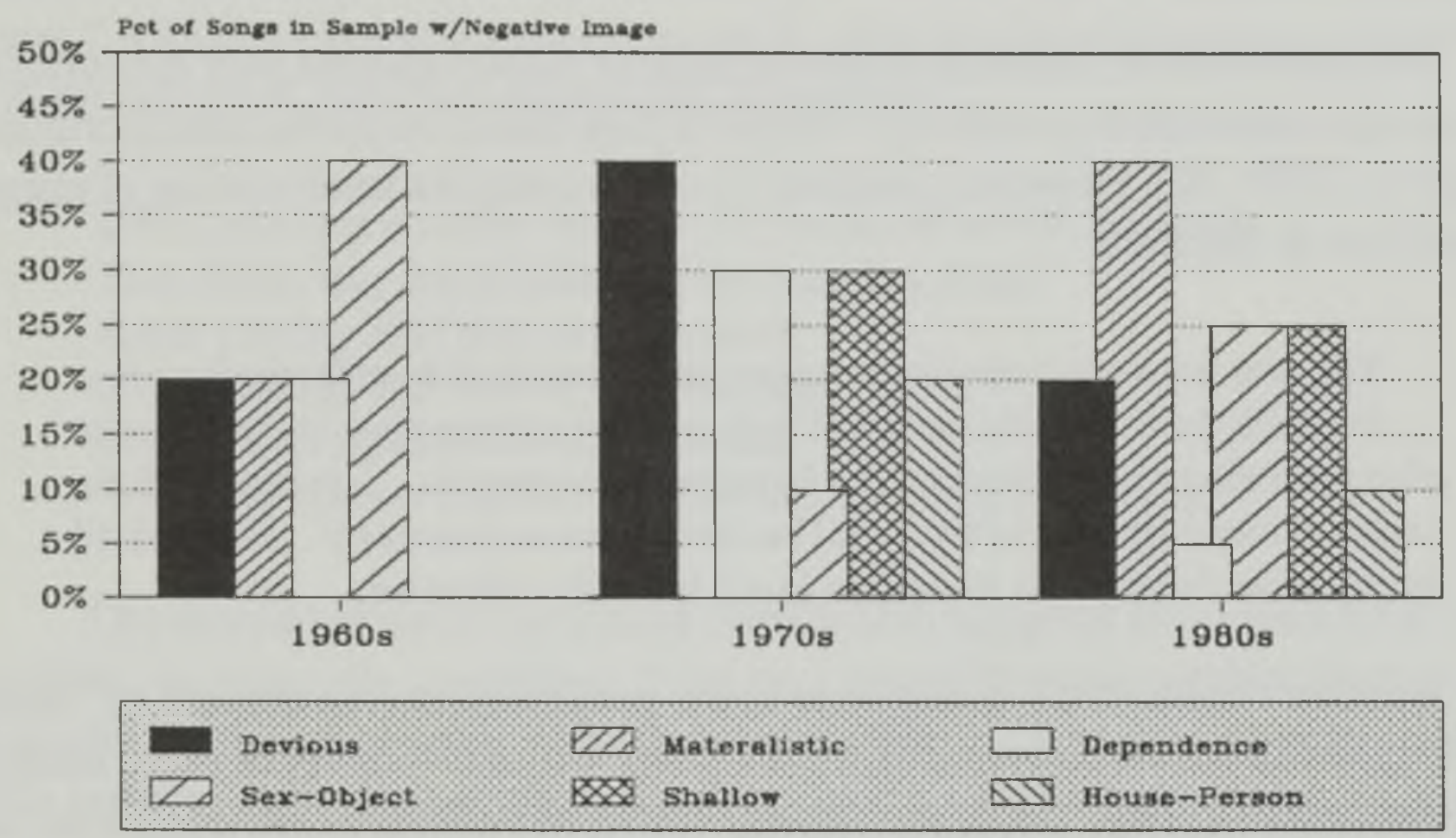

Comparison of Three Decades

\section{Discussion}

The meanings of these findings can best be explored within the sociological, economic and political contexts of the creation and performance of these songs. Holsti $(1969,35-37)$ presents us with both challenges and possibilities for making "inferences about effects of messages." Specifically, we must ask, what is the effect of the message on its recipient?

While it is risky, not to mention difficult to assay this question in an exploratory study using limited data, it may be useful to identify three trends that began to emerge in reaction to reggae late in the 1980s. One was a wave of attempts -- largely, though not exclusively, by women -- to use the media to decry popular lyrics depicting women thusly. Columnist Howard McGowan of The Daily Gleaner (30 December 1988) wrote of one concert that "... perhaps the single most distasteful situation came ... when the worst squalor was presented on stage for lyrics .... So vulgar was this section that the plug was rightly pulled on them ..." On 1 January 1989, The Sunday Gleaner carried another article in its "On the Record" section under the headline, "Time for a Stand Against Dirty Lyrics." Furthermore, The Daily Gleaner of 13 January 1989 devoted its "Letters to the Editor" page to public reaction to such lyrics. The following were some of the headings of these letters: 


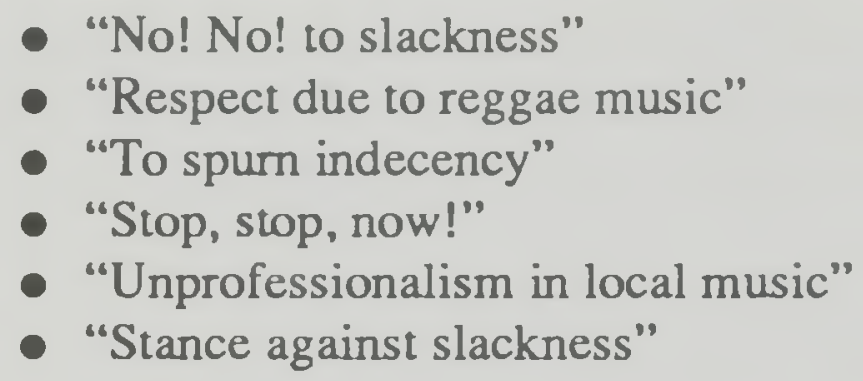

The government, mindful of the increasing public discord over the lyrics of these songs, responded by making it illegal to play music on public transportation. Cosgrove $(1989,60)$, However, reminds us of the complex intertwining of reggae and politics in Jamaica:

The war between conscious reggae and Dancehall is effectively a war ... in which the inevitable values of high and low culture play. After decades of suppressing rastafarianism, the Jamaican government ... recognized the exotic values of the rasta faith [and] has been keen to promote it ... Dancehall on the other hand ... is low-brow [and] lyrically offensive.

Another recent trend in response to the gender-offensive content of "dance hall" reggae is a denial-in-lyrics by female singers of the veracity of these images, and a demand that they "cease and desist," citing the effects of the continued use of such images. Red Dragon's popular song, "Hold a Fresh," which suggests that women are dirty and go to the dance halls with "moldy arms [pits]" for lack of washing, elicited a reaction-in-song by a female disc jockey to the effect that women observe proper hygiene and do not have "moldy arms." Sister Charmaine, one of the few successful female disc jockeys, sings in response to another song that her abilities are based on a careful diet and a daily regimen of exercise that keeps her body fit ("Me have the body if Control the Agony"). Bearing in mind the image of Caribbean women (they become fat and lazy as soon as they marry) expressed above by Barrow's (1986) male interview subjects, it may be accurate to conclude that a protracted gender struggle to establish the image of "the Caribbean woman" is taking place.

Songs in a similar vein have been released by dub poet Breeze and by Brown. Breeze's song "Get Back" tells male disc jockeys that they should abandon "slackness;" that when men pick up a microphone on stage they immediately bury women in shame and degradation, and women are tired of being demeaned by popular music. The song continues by reminding men that women are their daughters and sisters in the struggle; indeed, women are the mothers of Jah's creation. Brown's "Respect" scolds a man for ridiculing a woman because of her features. She takes the man to task for calling the woman ugly and encouraging others to ridicule her appearance. More importantly, Brown calls into question the male habit of using female anatomy as an object of entertainment and ridicule on the stage. The song concludes that such behaviour indicates lack of respect for women. 
The third trend to emerge in response to the salaciousness of dance hall reggae is, curiously enough, that women comprise much of the market for the songs in which their gender is degraded. Evidence reported in the popular press and provided by record stores shows that women are the major purchasers of these records and tapes, as well as enthusiastic fans of these songs at dance halls and concerts. This, despite lyrics such as those in Yellow Man's "Still Be a Lady/Titty Jump," which at once deny gender equality, demean female anatomy, and reduce it to an object of both voyeurism and commerce:

Girls, you cant do what the guys do you know an still be a lady

Titty jump, titty jump, make me see you titty jump!

Some gal titty stiff like elephant trunk

Some gal titty stiff like any tree stump

Some gal titty jump like any bull frog

When the brassiere come off it favour [resemble] thread bag.

The thread [money] bag image (which also suggests the connotation of bag as udder) is especially degrading. Women's sexuality is stigmatized here in terms of market value when sold. "The fact that women ... sometimes secret money in their bosom (a complex symbol of private space where women exercise absolute control of material and sexual resources) is demeaningly extended as the ultimate comic image of woman reduced to undignified, bare essentials" (Cooper 1990,47).

If women nevertheless will enjoy and buy such salaciousness, it may not be too much to agree with Cosgrove $(1989,46)$ that "a war is raging ... a battle which, when all is said and done, is . . . about the future of Jamaican culture ... . Reggae has fractured into two warring traditions.... Bob Marley sang about righteousness, the DJs sing about girls' breasts." Why reggae has split thusly, and why it holds women in such low regard cannot be answered in an exploratory study such as this. It is sufficient here to point out that rastafarianism and the music that gave it voice have had strong enough appeal to earn semi-embrace by the Jamaican polity, and that reggae, despite its original revolutionary message of dignity, spiritualism, and freedom for the downtrodden, has proffered mostly degradation, material exploitation, and the bondage of negative stereotypes to Jamaican women. Cutting a path to gender equity through the intertwining vines of religion, music, and politics in Jamaica must await further cultural mapping by social scientists. 


\section{APPENDIX}

No. Artist

1. Bob Marley \& The Wailers

2. The Heptones

3. Niney \& Maxie

4. Prince Buster

5. Desconond Dekker

6. Derrick Harriot \& D. Scott

7. Mayfals

8. Sung Hugh

9. Erric Smith

10. Peter Tosh

11. Yabby You

12. Pter Tosh

13. Brent Dowe

14. Meditations

15. Neville Martin

16. Reggae Philharmonic

17. Justine Hinds \& The Dominoes

18. Justine Hinds \& The Dominoes

19. Barrington Levy

20. Professor Nuts

21. Frankie Paul

22. Super Cat

23. Freddie McGregar

24. Junior Reid

25. General Echo

26. Yellow Man

27. Yellow Man

28. Steel Pulse

29. Bob Marley \& The Wailers

30. Admiral Bailey

31. Home T.

32. Bob Livingston

33. Lt. Stitchel

34. Gregory Isaacs

35. Barker B.
Tille (1970s) Tisle (1980s)

"You Are Mine"

"Draw Your Brakes"

"Swoet and Dandy"

"Woman Follow Man"

"Pitta Patta"

"Soon Corne"

"Happy Go Lucky"

"Brand New Second Hand"

"Build Me Up"

"Woman Is Like A Shadow"

"The Message"

"Minnie The Moocher"
"Sweet Lorraine"
"Miss Wendell"
"Come Horne"
"In A Di Bus"
"How I Love You"
"Swcets For My Swcets"
"Don't Hurt My Feelings"
"Married Life"
"Old Man Love Young Gal"
"Girls Can't Do What The Guys Dol
Titty Jump"
"Girls Pet"
"Leggo Beast"
"Pimpers Paradise"
"Punany"
"She Loves The Single Life"
"Two Years Old"
"Wear Yu Size"
"Private Beach Party"
"Can't Tie Me"

\section{NOTES}

'See, for example, "The Convention on the Elimination of All Forms of Discrimination Against Women," adopted by the U.N. General Assembly, 18 December 1979, U.N. G.A. Res. 34/180 (XXXIV). See also "Convention on the Political Rights of Women.” New York, 31 March 1953. 27 U.N.T. 1909.

${ }^{2}$ Recent works done in conjunction with the Women in the Caribbean Project, Institute of Social and Economic Research, University of the West Indies, inform this section.

${ }^{3}$ "Sitting here in limbo ... like a bird without a song ... I don't know where life will lead me ... knowing that I have to go."

${ }^{4}$ The preceding titles are the works of Jimmy Cliff, produced during the 1970s.

${ }^{5}$ This song by Neville Martin was done during the 1970s, and was used extensively by one political party during the election period. Among other things, it calls for "equal pay for women."

${ }^{6}$ The Daily Gleaner and The Star are major daily newspapers in Jamaica.

${ }^{7}$ Now defunct. 


\section{REFERENCES}

Amin, Tahir. 1986. Nationalism and Internationalism in Three Communitarian Traditions: Liberalism, Marxism \& Islam. Unpublished manuscript.

Anderson, Beverley J. 1990. Sports and Gender-Based Socialization in Jamaica. Arena Review 14: 1.

Anderson, Patricia. 1986. Conclusion: Women in the Caribbean. Social and Economic Research 35: 2.

Arche, Sergio and Oden Marichal, eds. 1982. Evangelization \& Politics. New York: Circus.

Ardner, S., ed. 1978. Defining Females. London: Croom Helm. - 1975. Perceiving Women. London: Dent.

Aronson, Elliot. 1972. The Social Animal. San Francisco: W.H. Freeman.

Barrow, Christine. 1986. Male Images of Women in Barbados. Social and Economic Research 35: 3.

Berelson, Bernard. 1952. Content Analysis in Communication Research. New York: Free Press of Glencoe.

Berger, Monroe. 1947. Jazz: Resistance to the Diffusion of a Culture Pattern. Journal of Negro History 32.

Berryman, Phillip. 1987. Liberation Theology. New York: Pantheon.

Biafra, Jello. 1987. The Far Right and The Censorship of Music. Harvard Law Review 84: 10.

Block, M., ed. 1975. Political Language and Oratory in Traditional Society. London: Academic Press.

Brodber, Erna. 1986. Afro-Jamaican Women at the Turn of the Century. Social and Economic Research 35: 3.

Brodber, Ema and J. Edward Green. 1981. Social and Economic Research, Series $C$.

Cameron, Deborah. 1985. Feminism and Linguistic Theory. London: MacMillan.

Chapple, Steve and Reebee Garofalo. 1977. Rock'n'Roll is Here to Pay. Chicago: NelsonHall.

Cooper, Carolyn. 1990. Slackness Hiding from Culture: Erotic Play in the Dance Hall. Jamaica Journal 23: 1\&2.

Cosgrove, Stuart. 1989. Slack-talk and Uptight. The New Statesman (July).

Davidson, W. P. 1947. An Analysis of the Soviet-Controlled Berlin Press. Public Opinion Quarterly 22.

Davis, Stephen and Peter Simon. 1979. Reggae Bloodlines: In Search of the Music and Culture of Jamaica. London: Heinemann Educational Books.

Denisoff, R. Serge. 1975. Solid Gold: The Popular Record Industry. New Brunswick, NJ: Transaction.

Duster, Troy. 1970. The Legislation of Morality. New York: Free Press.

Elder, J.D. 1968. The Male/Female Conflict in Calypso. Caribbean Quarterly 14: 3 (September).

Firth, Simon. 1986. Art Versus Technology: The Strange Case of Popular Music. Media Culture and Society 8.

Frazer, Elizabeth and Deborah Cameron. 1989. Knowing What to Say: The Construction of Gender Linguistic Practice. In Ralph Grillo, ed., Social Anthropology and the Politics of Language, Sociological Review Monograph 36. London: Routledge. 
Griffin, Susan. 1981. Pornography and Silence: Culture's Revenge Against Nature. New York: Harper \& Row.

Grillo, Ralph, ed. 1989. Social Anshropology and the Politics of Language, Sociological Review Monograph 36. London: Routledge.

Holsti, Ole R. 1969. Content Analysis for the Social Sciences and Humanities. Reading, MA: Addison-Wesley.

Horsley, Richard A. 1987. Jesus and the Spiral of Violence. New York: Harper \& Row. Kothari, Rajni. 1987. On Humane Governance. Alternatives 12: 3 (July).

Langley, Winston. 1985. The Banjul Charter on Human and People's Rights. Indian Political Science Review 20.

Lasswell, Harold D. 1942. Analyzing the Content of Mass Communications: A Brief Introduction. Document No. 11, Library of Congress, Experimental Division for Study of Wartime Communication.

Leonard, Neil. 1962. Jazz and the White American: The Acceptance of a New Art Form. Chicago: University of Chicago Press.

Massiah, Jocelyn. 1986. Establishing a Programme of Women and Development Studies in the University of the West Indies. Social and Economic Research 35: 1.

Pateman, Trevor. 1980. Language, Truth and Politics. Lewes: Jean Stroud.

Price, Ken. 1979. Endless Pressure. Penguin Books.

Rawls, John. 1971. A Theory of Justice. Cambridge: Harvard University Press.

Sacred Congregation for the Doctrine of the Faith. 1984. Instruction on Certain Aspects of Theology of Liberation. Boston: Daughters of St. Paul. 